\title{
La primacía de los derechos sociales relacionados con un nivel de vida adecuado: una reivindicación (in)esperada de la pandemia
}

\section{The primacy of social rights related to an adequate standard of living an (un)expected vindication of the pandemic}

\author{
Ana María Bonet de Viola \\ Doctora en Derecho \\ Universidad Católica de Santa Fe-CONICET - Argentina \\ Correo electrónico: abonet@ucsf.edu.ar
}

\author{
Elisabet A. Vidal \\ Doctora en Derecho \\ Universidad Católica de Santa Fe - Argentina \\ Correo electrónico: evidal@ucsf.edu.ar \\ Esteban Piva (iD) \\ Abogado \\ Universidad Católica de Santa Fe - Argentina \\ Correo electrónico: epiva@ucsf.edu.ar \\ Selene Saidler \\ Estudiante de Derecho \\ Universidad Católica de Santa Fe- Argentina \\ ssaidler@ucsf.edu.ar
}




\title{
Virginia Schierano \\ Abogada \\ Universidad Católica de Santa Fe- Argentina \\ Correo electrónico: vschierano@ucsf.edu.ar
}

\author{
Mariana del Pazo \\ Abogada \\ Universidad Católica de Santa Fe- Argentina \\ Correo electrónico: mdelpazo@ucsf.edu.ar,
}

\section{Resumen}

Este trabajo se propone mostrar cómo la pandemia originada por el COVID-19 ha provocado el replanteamiento de la mirada liberal de los derechos humanos que venía invalidando ya todo discurso acerca de su interdependencia e indivisibilidad. Al legitimar la limitación de ciertas libertades, a la vez que se ponderaba la urgencia de asegurar un nivel de vida adecuado para todos, la particular situación de emergencia mostró la postergación de la cual los derechos sociales vienen siendo objeto en el modelo jurídico vigente desde la Modernidad. La primacía y fundamentalidad de los derechos relacionados con un nivel de vida adecuado se ha postergado por un derecho que los dio por presupuestos. La situación de crisis presenta una nueva oportunidad para su reivindicación, en cuanto condición de realización de cualquier otro derecho, de cualquier convivencia social.

\section{Palabras clave}

Pandemia; COVID-19; derechos sociales; derechos humanos; nivel de vida adecuado.

Cómo citar este artículo:

Bonet de Viola, A. M., Vidal, E. A., Piba, E., Saidler, S., Schierano, V., \& Del paso, M. (2021). La primacía de los derechos sociales relacionados con un nivel de vida adecuado: una reivindicación (in)esperada de la pandemia. Revista de la Facultad de Derecho y Ciencias Políticas, 51 (134), pp. $83-99$.

doi: https://doi.org/10.18566/rfdcp.v51n134.a04

Recibido: 14 de septiembre de 2020

Aprobado: 12 de noviembre de 2020 


\section{Abstract}

This article intends to show how the pandemic caused by COVID-19 has developed the rethinking of the liberal view of human rights. In which invalidated discourses about their interdependence and indivisibility by legitimizing the limitation of freedoms. While they are weighing the urgency of ensuring an adequate standard of living for all. The emergency shows the postponement of which social rights are the object of the legal model in force since Modernity. The primacy and fundamentality of rights related to an adequate standard of living. They were postponed by a right that gave them for budgets. The crisis presents a new opportunity for their claim. As a condition of realization of any other right, as a condition of any social coexistence.

\section{Keywords}

Pandemic; COVID-19; social rights; human rights; the adequate standard of living.

\section{Introducción}

El 31 de diciembre de 2019 se detectó, en la ciudad de Wuhan, China, el primer caso de COVID-19, acrónimo de una nueva enfermedad llamada técnicamente coronavirus disease 2019, causada por el virus SARS-CoV-2 (Lana et al., 2020; Lu et al., 2020). Su alto nivel de transmisibilidad generó una rápida propagación. A los pocos días, el 9 de enero de 2020, la Organización Mundial de la Salud $(\mathrm{OMS})^{1}$ confirmó su circulación (WHO, 2020a) y el 30 de ese mismo mes, declaró la emergencia mundial (WHO, 2020b), activando el procedimiento aplicable a las emergencias de salud pública de alcance internacional (WHO, 2005). La intensa circulación de personas en el contexto global contribuyó a la acelerada expansión internacional de la enfermedad. El 23 de enero, la OMS reportó el primer caso en Estados Unidos (WHO, 2020), el 27 de febrero se registró el primero en Brasil y el 4 de marzo en Argentina y Chile (WHO, 2020c; 2020d).

La crisis sanitaria originada por la rápida propagación del virus obligó a los estados a adoptar ciertas medidas restrictivas de las libertades. Autorizados por el derecho (Art. 4 PDCP) ${ }^{2}$ y sobre todo legitimados socialmente, los estados

1 WHO, en sus siglas en inglés: World Health Organization.

2 El Artículo 4 del Pacto de los Derechos Civiles y Políticos (PDCP) habilita a los estados a suspender las obligaciones asumidas frente a situaciones excepcionales, declaradas oficialmente, que pongan en peligro la vida de la Nación. En consonancia, el Artículo 4 del Pacto de los Derechos Económicos, Sociales y Culturales (PIDESC) admite cierta limitación legal de los derechos en él reconocidos, en la medida compatible con esos derechos y con el exclusivo objeto de promover el bienestar general. Cf. Barrena, 2012, p. 37. 
hicieron uso de sus potestades instaurando diferentes formas de aislamiento y confinamiento para contener la expansión del virus ${ }^{3}$.

Estas cuarentenas fueron generando la retracción, y, en algunos casos, la paralización de ciertos sectores, cuando no de toda la economía (cf. Gargiulo, Bohoslavsky y Casas, 2020, p. 1). De esta manera la crisis sanitaria vino a profundizar otras crisis ya existentes como las sociales, económicas, alimentarias, que venían afectando ya a los sectores más vulnerables, como los desempleados, los trabajadores precarizados, como los autónomos, los ancianos, los sin techo, los refugiados, las personas con discapacidad, las mujeres, los presos (Sousa Santos, 2020, p. 45 ss.). A ellos, la cuarentena vino a sumar una vulnerabilidad coyuntural a su inestabilidad socioeconómica existente. A este escenario se sumó la expansión de las situaciones de vulnerabilidad a otros sectores hasta entonces no tan vulnerables, que de pronto vieron limitados sus ingresos, llegando incluso a experimentar una restricción de bienes fundamentales para alcanzar un nivel de vida adecuado.

La urgencia de responder tales restricciones puso inesperadamente en evidencia la primacía ${ }^{4}$ de los derechos relacionados con un nivel de vida adecuado, y los reivindicó, incluso frente a otros derechos tradicionalmente priorizados, como los de la libertad. El estado de crisis social desestabilizó la jerarquización que los derechos de la libertad venían obteniendo sobre los sociales que, a pesar de toda declaración formal de interdependencia e indivisibilidad de los derechos humanos, ${ }^{5}$ se venía ejerciendo en la desigual

3 La cuarentena total o general fue la decisión adoptada por los diferentes países para disminuir el riesgo de contagio de la enfermedad, la cual implica mantenerse en aislamiento social, preventivo y obligatorio, dentro de los hogares, evitando el menor contacto posible con el exterior. Las clases educativas son suspendidas, los negocios clausurados a excepción de aquellos que brindan servicios esenciales a la comunidad y se prohíbe la concurrencia a todo lugar público que implique concentración de personas. Asimismo, la ciudadanía solo puede circular frente a situaciones excepcionales - previamente autorizadas- tales como motivos de salud, trabajo o necesidad. La flexibilización de esta medida, Ilamada distanciamiento social, preventivo y obligatorio, surge cuando la curva de contagios se ha desacelerado y comienzan -paulatinamente- a habilitarse la realización de distintas actividades hasta que se alcanza la etapa final de 'nueva normalidad' que aparece tras registrar ningún contagio diario.

4 En el presente texto, el término 'primacía' se emplea para contraponer a la prioridad, que en la práctica jurídica han venido teniendo los derechos de la libertad. Ésta se correspondería con el carácter que, en el orden internacional, reconoce ciertos derechos humanos como la vida, que están vinculados al ius cogens. Esta primacía no afectaría la interdependencia e indivisibilidad, sino que tendría una función de restitución del equilibrio generado por la prioridad liberal de los derechos de primera generación.

5 Estas características fueron implícitamente expuestas en la Declaración Universal de Derechos Humanos (DUDH), al consagrar en un mismo texto tanto derechos civiles y políticos como económicos, sociales y culturales, principal antecedente para que la Asamblea General de las 
efectivización de su exigibilidad (cf. Bonet de Viola, 2016). La crisis pandémica puso en cuestión la jerarquía que habían ganado los derechos de la libertad, al mostrar el carácter esencial -y por lo tanto, primario- de los derechos sociales relacionados con el nivel de vida adecuado como la alimentación, la vivienda, la vestimenta, la salud, entre otros.

Este trabajo retoma tal premisa acerca de la primacía de tales derechos para ahondar en el concepto de nivel de vida adecuado que postula el Artículo 11 del Pacto Internacional de Derechos Económicos Sociales y Culturales (PIDESC). Se postula que esa primacía genera cierta irritación ${ }^{6}$ en la lógica de los principios de indivisibilidad e interdependencia de los derechos humanos, los cuales, hasta entonces, han venido incluso solapando la jerarquización que supieron ganar en la práctica jurídica los derechos de la libertad, sobre todo en lo referente a la exigibilidad.

En un primer apartado se profundiza la vinculación entre la crisis pandémica y la recuperación de la prioridad de los derechos vinculados a un nivel de vida adecuado.

En un segundo momento se analiza la cuestión del alcance de las responsabilidades respecto de la garantía del derecho humano a un nivel de vida dentro de los estándares.

El tercer apartado postula una redefinición ecológica de los parámetros progresistas y desarrollistas de definición de la adecuabilidad del nivel de vida.

Naciones Unidas (AGNU), por medio de su Resolución 32/130, afirmara el carácter indivisible e interdependiente de todos los derechos humanos y libertades fundamentales, instando, además, a los Estados a prestar la misma atención y consideración en lo que respecta a la aplicación, promoción y protección, tanto de los derechos civiles y políticos como a los derechos económicos, sociales y culturales (cf. Malavolta y Pulvirenti, 2020). En este sentido también la Declaración y el Plan de Acción sobre Derechos Humanos de Viena de 1993.

6 Se utiliza el término 'irritación' en el sentido de provocación, o estimulación, como lo utiliza el autor Gunther Teubern (2010). 


\section{Reivindicación de la prioridad de los derechos humanos relacionados con el nivel de vida adecuado}

Las crisis profundizadas por la pandemia -en primer lugar, sanitaria; luego, alimentaria, y también económica- requirieron del Estado un nivel de involucramiento especial, para articular las exigencias sanitarias de distanciamiento con los mecanismos impostergables tanto de provisión de bienes fundamentales -vg., alimentos, agua, energía-, como de tareas imprescindibles -vg., las de cuidado, entre las que cuentan los servicios de salud-.

De manera insólita la sociedad procedió a reclamar un mayor intervencionismo estatal en el control de la pandemia, incluso en la restricción de las propias libertades (Santos, 2020, p. 40), lo que legitima una mayor incidencia de intervencionismo estatal, principalmente en materia de seguridad sanitaria, así como en cuestiones relativas a la asistencia social, lo cual hizo resurgir, inclusive, la narrativa en torno al Estado Leviatán (Svampa/Viale, 2020, p. 3; Palermo, 2020, p. 41).

Este resurgimiento viene a interponerse a la creciente tendencia de minimización estatal (Mattei, 2013, p. 28). ${ }^{7}$ Justo cuando el récord de concentración del poder global de las corporaciones transnacionales parecía darles la razón a quienes pronosticaban un "Estado más liviano” (Nandy, 1996, p. 89), vino la crisis pandémica a reanimar a los aletargados sistemas estatales modernos con fuertes exigencias de respuesta inmediata, oportuna y efectiva, so pena de colapso total (cf. Santos, 2020, p. 73).

Más allá de la funcionalidad del Estado respecto del crecimiento económico y la regulación de la economía, en la cual ya venía siendo desplazado cada vez más por otros poderes transnacionales como las corporaciones o los organismos internacionales -como el FMI o el BM-, la pandemia impulsó una reconsideración del Estado en tres aspectos. Seguridad, salud pública y gestión social (asistencia social) constituyen las tres funciones que, frente a la crisis sanitaria y social, reactivaron el rol del Estado, sea como Leviatán (Svampa/ Viale, 2020, p. 3) o como principal “cuidador poblacional” (cf. Follari, 2020,

\footnotetext{
$\overline{7}$ El aumento de poder de las corporaciones transnacionales, plasmado en organizaciones internacionales como el Fondo Monetario Internacional (FMI), la Organización Internacional del Comercio (OMC), el Banco Mundial (BM) vino a desestructurar la hegemonía que a partir del fin de la Guerra Fría, con la hegemonía internacional que los Estados Nación detentaron desde su surgimiento en el siglo XVII (Cf. Mattei, 2013, p. 28).
} 
p. 10). Trilogía que reúne, sin embargo, modelos estatales dispares, pues, aunque la primera función traiga a colación discursos securitistas y de control, las dos segundas vienen vinculadas con discursos relacionados con enfoques del cuidado y los lazos colectivos (Sztulwark, 2020, p. 30).

La reactivación del Estado en estos sectores reivindicó, por un lado, su rol como garante de los derechos relacionados con un nivel de vida adecuado, pero por el otro mostró su efectiva incapacidad para cumplir tal cometido. En efecto, incluso abocado a las funciones esenciales -como la preservación de la vida, la salud, la alimentación y la seguridad-solo parece poder responder por ellas de manera limitada (Canelo, 2020, p. 20). Esta limitación se vio reforzada por la gravedad de la crisis, o de "las crisis superpuestas" y por la consecuente profundización de las vulnerabilidades ecosociales existentes. Limitación que, a su vez, rehabilita la reflexión acerca de las responsabilidades respecto del aseguramiento de un nivel de vida adecuado, y en lo atinente al alcance de tal nivel, es decir, acerca del concepto de adecuación del nivel de vida.

\section{Redefinición del rol del Estado como garante de los derechos sociales}

El derecho a un nivel de vida adecuado fue incorporado en el Artículo 25 de la DUDH ${ }^{8}$ y luego plasmado, de manera vinculante para los Estados firmantes, en el Artículo 11 del PIDESC ${ }^{9}$. Ambos artículos refieren al derecho a un nivel de vida adecuado en relación con el propio sujeto de derechos y con su familia, lo cual enfatiza su carácter autosatisfactorio. Es decir, que en principio, cada uno tiene derecho a satisfacer por sí mismo su derecho a un nivel de vida adecuado, y solo en caso de necesidad, a exigir su satisfacción ${ }^{10}$. En correlación con lo descrito, es menester del Estado, en primer lugar, generar una situación en la

8 Artículo 25.1 DUDH: "Toda persona tiene derecho a un nivel de vida adecuado que le asegure, así como a su familia, la salud y el bienestar, y en especial la alimentación, el vestido, la vivienda, la asistencia médica y los servicios sociales necesarios; tiene asimismo derecho a los seguros en caso de desempleo, enfermedad, invalidez, viudez, vejez y otros casos de pérdida de sus medios de subsistencia por circunstancias independientes de su voluntad".

9 Art. 11.1 PIDESC: "Los Estados parte en el presente pacto reconocen el derecho de toda persona a un nivel de vida adecuado para sí y su familia, incluso alimentación, vestido y vivienda adecuados, y a una mejora continua de las condiciones de existencia".

10 En la Declaración y el Plan de Acción sobre DDHH de Viena (1993) y las líneas de acción sobre el enfoque basado en derechos humanos consideran las necesidades como como derechos, todos fundamentales a partir la tesis de la integralidad de los derechos humanos. 
que cada uno pueda alcanzar, por sí mismo, un nivel de vida digno, y solo en caso de necesidad, la Nación ha de garantizar directamente el derecho ${ }^{11}$.

El Comité de los Derechos Económicos, Sociales y Culturales (CDESC) especifica en su observación número 12 -relativa al derecho a la alimentación como parte del derecho a un nivel adecuado-, que los casos de necesidad refieren a la incapacidad individual o grupal de disfrutar del derecho, por razones que escapan al control de los involucrados (CDESC, 1999, n. 15). La incapacidad puede deberse a causales subjetivas o externas. Las subjetivas remiten a restricciones físicas o mentales. Las incapacidades externas dependen de condiciones ajenas al sujeto, como catástrofes ambientales (por ejemplo, una inundación) o sociales (en el caso, por decir, de un estado de guerra). El carácter autosatisfactorio del derecho implica que la obligación del Estado comienza solo cuando ni el sujeto ni su familia -alcanza en principio a los obligados a proveer alimentos por el derecho de familia- se encuentran en condiciones de satisfacer el derecho.

La responsabilidad del Estado respecto a la garantía y realización de los derechos humanos suele desglosarse en tres aspectos: respeto, protección y cumplimiento; este último comprende, a su vez, la facilitación y el aseguramiento (CDESC, 2017).

La obligación de respeto se relaciona con el carácter autosatisfactorio del derecho al nivel de vida adecuado, puesto que significa que, en principio, el Estado se debe abstener de realizar cualquier acto que perjudique la plena realización del derecho por parte de los particulares. El Estado no debe obstaculizar la autorealización de este derecho. La obligación alcanza tanto a medidas políticas y económicas como a aquellas jurídicas, por lo que abarcaría también a leyes o sentencias que atenten contra la autosatisfacción del nivel de vida adecuado (CDESC, 2017, 12-13).

La obligación de proteger implica que el Estado debe impedir que terceros afecten la plena realización de tal derecho. El ente mayor ha de bloquear cualquier acto que atente contra tal autosatisfacción. Tal protección funciona tanto frente a particulares como frente a otros estados, organizaciones, corporaciones u otras instituciones que atenten contra el nivel de vida adecuado. Esta obligación implica, por lo tanto, una acción efectiva del Estado, sea por

11 En este sentido se viene interpretando el Art. 28 de la Declaración Universal de los Derechos Humanos. 
medios políticos, como por los jurídicos (legislativos o jurisdiccionales). Su violación acontece, también, por medio de la omisión.

La obligación de cumplir, garantizar o realizar (se suele denominar de las tres maneras) se relaciona con la efectivización del derecho, y según las circunstancias, puede tomar dos formas: la facilitación y la realización propiamente dicha. Estas obligaciones plasman el mandato del Artículo 28 de la Declaración Universal de los Derechos Humanos, de hacer plenamente efectivos todos los derechos humanos de todas las personas.

La facilitación se corresponde con el principio de autosatisfacción, pues significa que el Estado debe procurar la autosatisfacción, esto es, debe generar una situación en la que cada individuo pueda alcanzar un nivel adecuado para sí y su familia ${ }^{12}$. La obligación de realizar se corresponde con las descritas situaciones de imposibilidad personal o externa, cuando el Estado debe directamente procurar el nivel de vida, frente a la incapacidad involuntaria del sujeto.

Al afectar el acceso a bienes y servicios esenciales (sea por restricción de los ingresos, como de la movilidad), la crisis pandémica aumentó el estado de incapacidad voluntaria frente al derecho a un nivel de vida adecuado. Ello generó un traslado quasi automático de responsabilidad al Estado, que debió aumentar su performance en el ámbito de la garantía y realización efectiva. Este desempeño, como se comentó en el punto anterior, puso en evidencia los límites y carencias intrínsecas de la institución estatal moderna. En efecto, la cuestión del rol del Estado frente a la pandemia ocupó la mayoría de los ámbitos de debates académicos durante los primeros meses de cuarentena (cf. vg., Agamben, 2020; Svampa, 2020; Palermo, 2020).

Mientras tanto, proliferan las narrativas postdesarrollistas, ecológicas y periféricas que ponen en cuestión tanto al mercado como al Estado, en cuanto figuras que responden ambas a la lógica moderna del dominio y la explotación (Mattei, 2013, p. 55 ss.), raíz de las crisis ecosociales vigentes. Se habilita, así, una nueva arena de debate acerca de la 'redefinición' de las funciones estatales en torno a nuevas expectativas sociales. Redefinición que, esquivando la

\footnotetext{
12 En este sentido, puede entenderse la referencia de la observación n. ${ }^{\circ} 12$ del CDESC a la necesidad de que los estados adopten medidas para la optimización de los procesos de elaboración, preservación y reparto de alimentos, la difusión de aquellos principios vinculados a la nutrición y el adelanto de los sistemas agrícolas, con el objetivo de alcanzar un aprovechamiento y uso eficientes de los recursos naturales, así como de consolidar la asignación equitativa de los alimentos entre los países, de acuerdo con las carencias de cada país (Cf. CDESC, 1999).
} 
narrativa revolucionaria del siglo XX, se afianza en cambio en la expectativa de una ‘transición' hacia un Estado como institución de un gobierno centrado en el cuidado de lo común y en la protección de los vínculos de solidaridad sobre la exclusión y la fragmentación social (Canelo, 2020, p. 21).

\section{Por una redefinición ecológica de los parámetros de la adecuabilidad}

Tanto el Artículo 25 de la DUDH como el 11, del PIDESC, refieren a la incorporación de la alimentación, la vivienda y la vestimenta como aspectos fundamentales de este derecho. Sin embargo, la DUDH procura un mayor alcance, al vincular el concepto de nivel de vida adecuado con los de salud y bienestar, y al incorporar explícitamente en su descripción la asistencia médica, los servicios sociales y los seguros -especificado incluso para los casos de desempleo, enfermedad, invalidez, viudez, vejez y otros modos de pérdida de los medios de subsistencia independientes de la voluntad-. Esta diferencia, mientras muestra, por un lado, el potencial que puede adquirir este derecho, pone en evidencia, por el otro, cierta retracción de los Estados al momento de asumir obligaciones vinculantes ${ }^{13}$.

La referencia de ambos artículos a “toda persona” determina la universalidad del alcance personal del derecho, al procurar fijar un límite por debajo del cual nadie debe encontrarse (NU, 2018). La especificación de ese límite es materia compleja: los estados prefirieron evidentemente el concepto de adecuabilidad al de dignidad, para establecerlo. Ambos, sin embargo, son conceptos difusos, de difícil determinación, y que incluso podrían ser considerados respecto del límite como coincidentes. En relación con lo anterior existen estudios que intentan establecer ciertos parámetros de referencia, como aquellos que apuntan a determinar un nivel mínimo de existencia, u otros que aspiran a elevarlo a un "nivel digno”, como el de "línea de dignidad” (Larraín, 2002).

Estos parámetros muestran el amplio espectro que puede abarcar el concepto de adecuabilidad: desde un nivel existencial de aseguramiento de las necesidades mínimas, vinculado con la supervivencia, a un nivel de dignidad

13 Ello, en tanto la DUDH posee un carácter declarativo, mientras que los pactos al ratificarse adquieren vinculatoriedad, lo que implica, en caso de incumplimiento, una responsabilidad internacional (Cf. Barrena, 2012, p. 13). 
que alcanzaría otros factores mucho más abarcativos, complejos e incluso difusos relacionados con la realización humana (Mora Rodríguez, 2009, p. 11).

Respecto de la determinación del nivel mínimo de existencia o necesidad, vinculable con el inciso segundo del Artículo 11 del PIDESC referente al derecho a no sufrir hambre, cabría menos margen de oscilación. Podría identificarse, según la referencia del propio artículo, con la alimentación, vestimenta y vivienda, para el caso, en su más esencial condición. A propósito, la cuarentena permitió evidenciar cierto nivel mínimo de esencialidad. Aquello que no pudo detenerse, incluso frente a las más duras exigencias de aislamiento, ${ }^{14}$ podría ser considerado un mínimo esencial.

En cualquier caso, así como el derecho a una alimentación adecuada implica mucho más que el derecho a no sufrir hambre (CDESC, 1999), podría interpretarse que el derecho a un nivel de vida adecuado implica mucho más que el derecho a sobrevivir, a no sufrir carencias de bienes esenciales -como alimentos, vestimenta y vivienda-. La determinación de este segundo nivel de adecuabilidad implica, sin embargo, no solo la consideración de factores socioculturales (Ziegler, 2002, p. 64) sino también una reflexión crítica acerca del nivel de vida postulado como modelo civilizatorio por un desarrollismo progresista ecosocialmente insostenible (cf. Mora Rodríguez, 2009). El derecho a una constante mejora de la calidad de vida se muestra, así como una traducción jurídica de la idea moderna de progreso (esencialmente individual), ilimitado, de una mejoría siempre in crescendo (Sozzo, 2014). Ello ha permitido, por un lado, la satisfacción de las necesidades básicas, pero la dinámica lineal de este desarrollo ha contribuido, por otro, a promover un nivel de consumo y explotación ecosocialmente insostenible.

Este enfoque progresista, que se deja entrever en la referencia del Artículo 11 del PIDESC, es atinente al derecho al mejoramiento constante de las condiciones de existencia. La idea de mejoramiento constante, sin referencia a algún límite, podría ser identificada con la dinámica consumista y expansiva del mercado, que procuraría establecer un límite mínimo lo más alto posible,

14 Se refiere a las actividades exceptuadas del aislamiento social obligatorio. El Artículo 6 del Decreto 297/20 estableció cuáles eran las actividades y servicios declarados esenciales durante la emergencia que estaban exceptuadas de cumplir con el aislamiento social, preventivo y obligatorio y con la prohibición de circular que entró en vigencia en todo el territorio de la República Argentina a partir de las 00 horas del 20 de marzo de 2020. Las que permanecieron funcionando en momentos de máxima restricción fueron aquellas tendientes a garantizar la producción y provisión de alimentos y medicamentos; los servicios de salud y servicios básicos, las fuerzas de seguridad y los servicios de justicia fundamentales. 
pero sin aceptar límite máximo, lo cual plantea una problemática respecto a la sostenibilidad ecosocial. Por eso, una revisión crítica de este artículo debería advertir acerca del riesgo de identificar el nivel de vida adecuado con el modelo de convivencia desarrollista hegemónico -consumista, frívolo y socioecológicamente insostenible -que la globalización civilizatoria procuró expandir (cf. Sachs, 1996; Sousa Santos, 1998, p. 37; Larraín, 2002, p.3, 4; Foster, 2020, p. 59).

En cambio, la referencia a un mejoramiento de las condiciones de existencia podría encontrar un sentido en relación con la superación de las tantas situaciones de miseria existentes (NU, 2018). Miseria que, sin embargo, debería ser claramente diferenciada de otras condiciones de vida diversas a las postuladas por el modelo civilizatorio del consumo, que incluso, en una mayor armonía con lo no humano, viven en la "abundancia de la tierra" (Gudynas, 2009, p. 192). La consideración de esta diversidad de estilos de vida ‘adecuados' implicaría un enfoque socioecológico de este derecho en función del contexto sociocultural y ambiental del sujeto, su familia y su comunidad.

En un enfoque ecológico, el concepto de nivel de vida adecuado debería, incluso, tener en cuenta no solo a todos los humanos sino también a todo lo no-humano que habita el planeta. Una revisión de la narrativa antropocentrista de los derechos humanos podría, inclusive, contribuir a su transformación en derechos ecológicos, en cuanto reguladores de una convivencia entre todos los seres que habitan el ecosistema del planeta Tierra. Una perspectiva alternativa local al nivel de vida adecuado desarrollista podría ser rastreada en la cosmovisión andina del buen vivir (cf. vg. Gudynas, 2009, p. 214) ${ }^{15}$. El aseguramiento de una "buena vida"para todos, o una "vida en plenitud" -entendida como armonía con la comunidad, con la naturaleza y con lo divino (Vanhulst y Beling, 2013, p. 4)- podría servir como variación local para especificar el carácter de adecuabilidad.

La recuperación de los vínculos de armonía y equilibrio tanto con la comunidad como con la naturaleza puede contribuir a una revisión del estilo de vida consumista promovido por el marketing de una economía en tensión

15 Se denomina académicamente 'buen vivir' al conjunto de cosmovisiones andinas (denominadas Sumak Kawsay (quechua), Suma Qamaña (aymara), Ñandereko (guaraní), Shïr wareas (ashuar), Küme Mongen (mapuche), Balu Wala (kuna)), en particular respecto de su común postulado de una vida en armonía y equilibrio entre humano y naturaleza (Cf. Jiménez, 2011). La recuperación académica de estas cosmovisiones se plasmó jurídicamente en las constituciones de Ecuador (2008) y Bolivia (2009). 
permanente por aumentar la cantidad de recursos disponibles y atender a la mayor cantidad de 'necesidades' posibles (cf. Melo Cevallos, 2015).

La 'plenitud' del buen vivir como armonía -entre los ayllus (miembros de la comunidad) y con la naturaleza en todas sus expresiones: sacha, allpa (selva/ tierra), yacu, jita (agua, lagunas, ríos), huaira (viento), aicha (animales), supai (espíritus)” (Vallejo y Sánchez, 2010)-, como visión holística, donde el hombre y la naturaleza forman parte de un todo inescindible (Piva, 2019), podría, así, constituir una alternativa al término ‘desarrollo’ como criterio de máxima de la adecuabilidad.

\section{Perspectivas}

La crisis pandémica dio lugar inesperadamente a una anhelada reivindicación de los derechos sociales, sobre todo de aquellos relacionados con la garantía de un nivel de vida adecuado. Las medidas de contención adoptadas durante la pandemia, como las cuarentenas, podrían considerarse como una confirmación efectiva de los alcances de un nivel mínimo de vida, de existencia, de supervivencia, lo cual podría contribuir al establecimiento local de ciertos criterios de adecuabilidad mínima. En refuerzo de esta búsqueda de aseguramiento de un mínimo han proliferado, durante la cuarentena, distintas voces que se proponen recuperar la idea del establecimiento de un ingreso básico universal (Svampa/Viale,2020, p. 98; Papa Francisco 2020, p. 40; Matarrita Arroyo, 2020; Felperín, 2020; Boulay, 2020; Ámbito, 2020; Rodríguez Martínez, 2020; DW, 2020; Noticias ONU, 2020) ${ }^{16}$.

La pandemia, sin embargo, expuso la insostenibilidad ecológica del modelo de convivencia social que sostiene como modelo el nivel de vida, - de consumo y de derroche- de los países más opulentos. Por eso, mientras que la crisis mostraba la necesidad de asegurar un nivel mínimo para cada uno, también mostraba la necesidad de replantear un modelo que no admite máximos.

Esta necesidad de replanteamiento del modelo hegemónico desarrollista impulsa el rastreo de criterios alternativos locales de adecuabilidad. En este

16 Con antecedentes lejanos como la Utopía de Tomás Moro, estas propuestas, incluso en sus diferencias, tienen en común la postulación de un sistema de aseguramiento de un ingreso, salario o renta básica, mínima para todas las personas, independientemente de su situación económica, en vistas a garantizar, de manera universal, incondicional y efectiva un nivel mínimo de vida (Cf. Lo Vuolo, 2016; Felperín, 2020). 
sentido, los conceptos vinculados al buen vivir - como buena vida, plenitud, armonía, equilibrio- podrían contribuir para una interpretación ecológica del derecho a un nivel de vida adecuado.

La adecuabilidad de la buena vida no vendría determinada por un cúmulo de necesidades específicas satisfechas, indiferentes a cualquier costo, establecidas como un piso por debajo del cual la dignidad del sujeto se vería violada. Antes bien, se configuraría como plenitud de vida, como armonía con los demás miembros de la comunidad, con la naturaleza, y con el ambiente -aún sea una ciudad, dado que el territorio se vuelve parte de la cultura e identidad de la comunidad (cf. Altmann, 2016)-. Esta plenitud conlleva repensar el concepto de nivel de vida adecuado en una perspectiva ecológica de los derechos, ya no solo humanos sino propiamente ecológicos con miras a procurar una buena vida para todos los habitantes de la Casa Común (Papa Francisco, 2015), tanto humanos como no humanos. Plenitud de difícil medición en parámetros occidentales, los cuales, tal vez, deberían también revisarse. Plenitud que daría lugar a una redefinición del derecho a un nivel de vida adecuado como aseguramiento de las condiciones socioecológicas, para que cada uno pueda llevar adelante una buena vida.

\section{Referencias}

Agamben, G. (2020). La invención de una epidemia. En: Amadeo, P., Sopa de Wuhan. Pensamiento contemporáneo en tiempos de pandemia. ASPO.

Altmann, P. (2016). Buen vivir como propuesta política integral: dimensiones del Sumak Kawsay.

Ámbito. (2020). Raverta sobre renta básica universal: Es una discusión que trasciende la Argentina. (27/7/2020). Ámbito, pp. 1-3 . https://www.ambito.com/ politica/renta-basica-universal/raverta-es-una-discusion-que-trasciende-laargentina-n5120278.

Barrena, G. (2012). Pacto Internacional de Derechos Civiles y Políticos, Comisión Nacional de los Derechos Humanos. Recuperado de: XXX

Bohoslavsky, P. (2020) (5 de mayo de 2020). Derecho a la alimentación adecuada y los desafíos de las políticas públicas durante la pandemia. Facebook: AGREGAR EL URL.

Bonet de Viola, A. M. (2016). Consecuencias de la clasificación de los derechos humanos en generaciones en relación a la justiciabilidad de los derechos sociales. Revista de la Facultad de Derecho y Ciencias Políticas, 46(124), pp. 17-32. https:// doi.org/10.18566/rfdcp.v46n124.a02.

Boulay, C. (2020). Pertinencia de una renta básica universal en América Latina en tiempos de pandemia. La Diaria, URL del artículo 
Canelo, P. (2020). Igualdad, solidaridad y nueva estatalidad. En A. Grimson (Ed.). El futuro después del COVID-19. Recuperado de XXX

CDESC. (1999). Observación general No 12 : El derecho a una alimentación adecuada (artículo 11 del Pacto Internacional de Derechos Económicos, Sociales y Culturales), 12 Mayo 1999,

CDESC. (2017). Observación general núm. 24 sobre las obligaciones de los Estados en virtud del Pacto Internacional de Derechos Económicos, Sociales y Culturales en el contexto de las actividades empresariales. E/C.12/GC/24.

Deutsche Welle. (29.05.2020). Renta básica: una propuesta más actual que nunca en tiempos de pandemia. Deutsche Welle. Recuperado de https://www.dw.com/ es/renta-b\%C3\%A1sica-una-propuesta-m\%C3\%A1s-actual-que-nuncaen-tiempos-de-pandemia/a-53623690\#: :text=El\%20Mundo-,Renta\%20 b\%C3\%A1 sica\%3A\%20una\%20propuesta\%20m\%C3\%A1s\%20actual\%20que\%20 nunca\%20en\%20tiempos,y\%20ejemplos\%20sobre\%20el\%20tema. (18/02/2021).

Felperín, M. (2020). El derecho a la renta básica o ingreso ciudadano universal. Rosario: UNR.

Follari, R. (2020). Después del aislamiento. En A. Grimson (Ed.). El futuro después del COVID-19. Argentina Futura: Recuperado de: https://www.argentina.gob.ar/ sites/default/files/el_futuro_despues_del_covid-19.pdf(18/02/2021)

Foster, R. (2020). Más allá del neoliberalismo: el Estado social el día después. En A. Grimson (Ed.). El futuro después del COVID-19. Argentina Futura: Recuperado de: https://www.argentina.gob.ar/sites/default/files/el_futuro_despues_del_covid-19. $\operatorname{pdf}(18 / 02 / 2021)$

Gargiulo, P., Bohoslavsky, P. y Casas, G. (2020). El (falso) dilema entre economía y derechos humanos. Buenos Aires:: Andhes.

Gudynas, E. (2009). Diez tesis urgentes sobre el nuevo extractivismo. Contextos y demandas bajo el progresismo sudamericano actual. Quito: CAAP-CLAES.

Jiménez, R. (2011). Rescatar y valorar otros pilares éticos. El Buen Vivir. FnGm.

Lana, R. M., Coelho, F. C., Da Costa Gomes, M. F., Cruz, O. G., Bastos, L. S., Villela, D. A. M., \& Codeço, C. T. (2020). The novel coronavirus (SARS-CoV-2) emergency and the role of timely and effective national health surveillance. Cadernos de Saude Publica, 36(3). https://doi.org/10.1590/0102-311x00019620

Larraín, S. (2002). La línea de dignidad como indicador de sustentabilidad socioambiental. Polis, Revista Latinoamericana (3). https://journals.openedition.org/polis/7695

Lo Vuolo, R. (2016). El ingreso ciudadano en debate: Repensar el bienestar en el siglo XXI. Nueva Sociedad, 264, 50 - 62.

Lu, H., Stratton, C. W., \& Tang, Y. W. (2020). Outbreak of pneumonia of unknown etiology in Wuhan, China: The mystery and the miracle. Journal of Medical Virology, 92(4), 401-402. https://doi.org/10.1002/jmv.25678

Malavolta, V. y Pulvirenti, O. (2020). Pandemia Covid-19: derecho a la salud y su tutela estatal. SAIJ, DACF200041.

Matarrita Arroyo, M. (2020). La renta básica universal en tiempos de pandemia. Recuperado de: https://delfino.cr/2020/04/la-renta-basica-universal-en-tiemposde-pandemia

Mattei, U. (2013). Bienes comunes. Un manifiesto. Madrid: Trotta.

Melo Cevallos, M. (Ed.) (2015). El buen vivir y su tutela jurídica en la jurisprudencia de la Corte Constitucional ecuatoriana. Quitor: Editorial Melo Cevallos. 
Mora Rodríguez, A. (2009). La racionalidad de la economía capitalista y la vida digna de las personas. Papeles, 107, 11-31. https://www.fuhem.es/media/cdv/file/biblioteca/ revista_papeles/107/la_racionalidad_de_la_economia_capitalista_A.MORA.pdf

Nandy, A. (1996). AGREGAR NOMBRE DÉL CAPÍTULO. En W. Sachs (E-d.). Diccionario del Desarrollo. Una guía del conocimiento como poder. Lima: Pratec.

Noticias ONU. (7 de mayo de 2020). Tras la aparición del coronavirus, ¿ha dejado de ser una utopía la renta básica universal?Noticias ONU. https://news.un.org/es/ story/2020/03/1470701

NU, Naciones Unidas. (2018). 70 años de la Declaración Universal de Derechos Humanos: Artículo 25. Oficina del Alto Comisionado para los Derechos Humanos. Recuperado de https://www.ohchr.org/sp/Pages/Home.aspx

Palermo, V. (2020). El coronavirus, Argentina y la compresión del tiempo. En A. Grimson (Ed.). El futuro después del COVID-19. Argentina Futura: Recuperado de: https://www.argentina.gob.ar/sites/default/files/el_futuro_despues_del_covid-19. $\operatorname{pdf}(18 / 02 / 2021)$

Papa Francisco. (2015). Encíclica Laudato Si': por el cuidado de la casa común. Roma: Editorial Vaticano. Recuperado de: http://www.vatican.va/content/francesco/ es/encyclicals/documents/papa-francesco_20150524_enciclica-laudato-si.html $(18 / 02 / 2021)$

Papa Francisco. (2020). La vida después de la pandemia. Roma: Librería Editrice Vaticana. Recuperado de: https://doi.org/10.2307/j.ctvdtpjpk.15

Piva, E. (2019). Buen vivir y sumak kawsay: algunas aproximaciones. Anuario de Ecología Integral y Desarrollo Sustentable, 2019, 25 - 27.

Rodríguez Martínez, M. (16 de abril de 2020). Renta básica universal:¿el (futuro) estado del bienestar post-coronavirus? Euronews,

Sachs, W. (Ed.). (1996). Diccionario del desarrollo. Una guía del conocimiento como poder. Lima: Pratec. https://doi.org/10.5755/j01.eee.111.5.347.

Sousa Santos, B. D. (2020). La cruel pedagogía del virus. Buenos Aires: Clacso.

Sousa Santos, B. D. (1998). La globalización del derecho: Los nuevos caminos de la regulación y la emancipación. Santa Fe de Bogotá: Universidad Nacional de Colombia.

Sozzo, G. (2014). Los nuevos modelos constitucionales alternativos al desarrollo en América del Sur (buen vivir y desarrollo perdurable en la arena del derecho). Revista de Derecho Ambiental, 40, 77-98.

Svampa. M y Viale, E. (2020). Hacia un gran pacto ecosocial y económico. En A. Grimson (Ed.). El futuro después del COVID-19. Argentina Futura: Recuperado de: https://www.argentina.gob.ar/sites/default/files/el_futuro_despues_del_covid-19. $\operatorname{pdf}(18 / 02 / 2021)$

Svampa, M. (2020). Pensando el post-coronavirus. Reflexiones sistémicas. Fundación Solón. Recuperado de: Youtube: https://www.youtube.com/watch?v=IfgYQ1BnfRY \&list=PLdfbN3k6M6oUYuHKtky Ly-QLLwrjTw0S0\&index=2\&t=0s (18/02/2021)

Sztulwark, D. (2020). La crítica y el "Estado fuerte". En A. Grimson (Ed.). El futuro después del COVID-19. Recuperado de XXX.

Vallejo, I., y Sánchez, D. (2010). Del antropocentrismo y el naturalismo a otras racionalidades y ontologías. Letras Verdes, (7), 3-6.

Vanhulst, J. y Beling, A. E. (2013). Buen vivir: la irrupción de América Latina en el campo gravitacional del desarrollo sostenible. Revista Iberoamericana de Economía Ecológica, 21, 1-14. 
WHO, World Health Organization. (2020). Novel Coronavirus (2019-nCoV) Situation Report 3. https://www.who.int/docs/default-source/coronaviruse/situationreports/20200123-sitrep-3-2019-ncov.pdf?sfvrsn=d6d23643_8 .

WHO, World Health Organization. (2020a). Novel Coronavirus (2019-nCoV) Situation Report 10. https://tinyurl.com/wbj34qf.

WHO, World Health Organization. (2020b). Novel Coronavirus (2019-nCoV) Situation Report 11. https://tinyurl.com/uknay46.

WHO, World Health Organization. (2020c). Novel Coronavirus (2019-nCoV) Situation Report 38. https://tinyurl.com/sqacl3q.

WHO, World Health Organization. (2020d). Novel Coronavirus (2019-nCoV) Situation Report 44. https://tinyurl.com/umtahd5.

WHO, World Health Organization. (2005). IHR Procedures concerning public health emergencies of international concern (PHEIC). Strengthening health security by implementing the International Health Regulations. https://www.who.int/ihr/ procedures/pheic/en/

Ziegler, J. (2002). Los nuevos amos del mundo y los que le resisten. París:Ediciones Fayard. 